\title{
Prediction of the Nutrient Content in Dairy Manure Using Artificial Neural Network Modeling
}

\author{
L. J. Chen, ${ }^{\star}$ L. Y. Cui, ${ }^{\star}$ L. Xing, $†$ and L. J. Han ${ }^{\star 1}$ \\ ${ }^{*}$ College of Engineering, China Agricultural University (East campus), 17 Qing-Hua-Dong-Lu, Hai-Dian District, Beijing 100083, P. R. China \\ †Service Center for Trading Technology Service, Chinese Academy of Agricultural Mechanization Sciences, Beijing 100083, P. R. China
}

\begin{abstract}
Nutrients in animal manure are valuable inputs in agronomic crop production. Timely and reliable information on animal manure nutrient content will facilitate the utilization of manure as organic fertilizer and reduce any associated potential environmental problems. The objective of this study was to investigate the feasibility of using multiple linear regression (MLR), polynomial regression, and artificial neural network (ANN) models to determine nutrient content in dairy manure. Fresh manure samples $(\mathrm{n}=86)$ from Holstein dairy cattle were collected from 34 dairy farms located in Beijing city, China. All samples were analyzed for nutrient content (ammonium nitrogen, total potassium, total nitrogen, and total phosphorus) by standard laboratory methods. The physicochemical properties (specific gravity, electrical conductivity, and $\mathrm{pH}$ ) of dairy manure samples were measured. Relationships between nutrient content and physicochemical properties were explored by MLR, polynomial regression, and ANN models. Several parameters $\left(\mathrm{R}^{2}\right.$, modeling efficiency statistic, mean squared error of prediction, mean bias, linear bias, and maximum bias) were calculated to evaluate model performance. The residual analysis results indicated that all MLR models for the testing data set had significant mean and linear bias. When compared with MLR and polynomial regression models, the ANN model for all nutrient contents had better performance with higher $\mathrm{R}^{2}$ and modeling efficiency statistics and lower mean squared error of prediction, mean bias, linear bias, and maximum bias. These findings demonstrated that the ANN model may be an appropriate tool to predict dairy manure nutrient content.
\end{abstract}

Key words: artificial neural network, dairy manure, nutrient content, physicochemical property

Received December 29, 2007.

Accepted August 18, 2008.

${ }^{1}$ Corresponding author: hanlj@cau.edu.cn; clj1020@googlemail.com

\section{INTRODUCTION}

Animal manure contains a variety of plant nutrients that are recycled in agronomic systems for the production of food and fiber for humans and feeds for livestock (Zhang et al., 2002). Therefore, animal manure has been and remains an important fertilizer and soil conditioner. Although well-applied manure has numerous positive attributes, excessive amounts of manure applied to land will generate environmental problems (Cooperband and Good, 2002). Excessive N will flow into the environment by 2 main pathways: ammonia volatilization and nitrate leaching. Ammonia volatilization will adversely affect air quality and nitrate leaching will lead to groundwater contamination (Vervoort et al., 1998). The primary environmental concern with phosphorus is the possibility of P-laden soil eroding into surface waters, resulting in eutrophication (Cooperband and Good, 2002). Excessive K may leach to the groundwater and affect its quality, although $\mathrm{K}$ is generally not considered to be a groundwater pollutant (Fulhage, 1990). Therefore, reliable information on the nutrient content of animal manure will facilitate its utilization as organic fertilizer and reduce any associated potential environmental problems.

Manure nutrient concentration can vary substantially and is affected by many factors, such as species, age, and diet of the animal (Wilkerson et al., 1997). Therefore, the use of book values to estimate nutrient concentration can be highly inaccurate. Traditional analyses in the laboratory provide high precision, but are expensive in terms of time and resources, being less attractive for practical applications (Singh and Bicudo, 2004; LugoOspina et al., 2005). There has been ongoing interest in developing rapid methods for estimating nutrient concentration in animal manure using physicochemical models that relate the nutrient content with physicochemical properties; for example, specific gravity (SG), electrical conductivity (EC), and pH (Stevens et al., 1995; Van Kessel et al., 1999; Lugo-Ospina et al., 2005). Some studies (Van Kessel and Reeves, 2000; Moral et al., 2005) have shown that there is a significant correlation between total $\mathrm{N}(\mathbf{T N})$, total P ( TP). and SG, and 
between ammonium nitrogen $(\mathbf{A N})$, total $\mathrm{K}(\mathbf{T K})$, and EC. Later, multiple linear regression (MLR) methods were adopted to improve model accuracy (Scotford et al., 1998). Scotford et al. (1998) observed that TP was most closely related to $\mathrm{SG}$ and $\mathrm{pH}$ in a multivariate analysis for agricultural slurries (cattle and pig) in the United Kingdom, Ireland, Germany, and Italy. Recently, similar models have been reported in our previous studies (Yang et al., 2006; Xing and Han, 2007).

The main limitation of previous studies is that only linear models were considered. Some studies have shown that linear models failed to provide satisfactory prediction of nutrient content in some animal manures (Scotford et al., 1998; Lugo-Ospina et al., 2005). LugoOspina et al. (2005) observed a poor linear relationship between TP and SG in dairy manure, with an $\mathrm{R}^{2}$ value of 0.34. Scotford et al. (1998) found that the linear relationship between TK and EC was very weak for cattle and pig slurries in all countries under consideration except Germany. In the United Kingdom, Ireland, and Italy, the best regression of TK on EC resulted in an $\mathrm{R}^{2}$ value of 0.192 . The artificial neural network (ANN) is a new analytical tool based on models of neurological structures and processing function in the brain. The comparative advantage of ANN over more conventional econometric models such as MLR and polynomial regression (PNR) models (Lugo-Ospina et al., 2005) is that it can model complex, possibly nonlinear relationships without any prior assumptions about the underlying data-generating process (White, 1990). Because of these features, ANN have been widely used in animal science (Berg et al., 1998; Fernández et al., 2006). The objective of this paper is to present various applications of the ANN in rapid estimation of dairy manure nutrient content.

\section{MATERIALS AND METHODS}

\section{Manure Samples}

Fresh manure samples $(\mathrm{n}=86)$ from Holstein dairy cattle were collected from 34 dairy farms located in 3 districts (HaiDian, Changping, and Yanqing) of Beijing, China, over a 2-mo period in fall 2004. Approximately two-fifths of the study farms fed TMR. The remaining three-fifths did not feed TMR and provided feeds individually (corn silage, sorghum silage, alfalfa hay, grain mix, protein mix, and minerals). These manure samples came from a variety of animal growth stages (calves, young heifers, mature heifers, dry cows, and lactating cows). Within the same dairy farm, only one sample for each growth stage was taken. To obtain a sample that was as representative as possible of the entire herd for every growth stage, about $10 \mathrm{~kg}$ of fresh manure was scraped from the ground at 6 different points and pooled. The average time of manure storage until sampling was about $1 \mathrm{~d}$. Samples were kept as cool as possible after collection. Upon arrival at the laboratory, samples were mixed in the sample container with a laboratory spatula, subsampled into smaller containers, and stored at $4^{\circ} \mathrm{C}$.

\section{Laboratory Analysis}

One part of each original sample was used to determine physicochemical properties (EC, $\mathrm{pH}$, and $\mathrm{SG}$ ), and the other part to determine concentrations of DM, AN, TK, TN, and TP. For determining physicochemical properties of manure samples, the solid samples were diluted 3-fold with water. The EC and $\mathrm{pH}$ of diluted manure samples were measured using a conductivity meter (model HI9835, Hanna Instruments Italia Sri, Padua, Italy) and a pH meter (model HI9024, Hanna Instruments Italia Sri), respectively. Both meters had automatic temperature compensation probes. The SG of diluted manure samples was determined by a hydrometer having a scale of 1.000 to $1.050 \mathrm{~g} / \mathrm{cm}^{3}$ (model 09000123, Yanhe Glass Instrument Company, Cangzou City, China). During analysis of SG, EC, and pH, particular attention was paid to the previous homogenization and mixing of the sample. Readings were taken within a few seconds of immersion in the slurry to avoid errors due to the sedimentation process (Chescheir et al., 1985).

The raw samples without dilution were used to determine DM, AN, TK, TN, and TP. Dry matter was determined by oven drying a weighed amount of the sample at $105^{\circ} \mathrm{C}$ to constant weight. Ammonium N was determined by steam distillation (APHA, 1998). Total $\mathrm{N}$ was determined by the Kjeldahl method (APHA, 1998). Total $\mathrm{P}$ was determined after microwave digestion in nitric acid (US Environmental Protection Agency, 1995) using colorimetric detection base on APHA (1998). Total K was determined in the above digestion by atomic absorption spectrophotometry (APHA, 1998).

\section{Data Set}

The manure nutrient content and physicochemical parameters were randomly divided into 3 subsets. The first subset was the training set $(\mathrm{n}=43)$, which was used for computing the gradient and updating the network weights and biases. The second subset $(\mathrm{n}=22)$ was the validation set. The error on the validation set was monitored during the training process. The validation error normally decreases during the initial phase of training, as does the training set error. However, when 
the network begins to overfit the data, the error on the validation set will typically begin to increase. When the validation error increases for a specified number of iterations, the training was stopped, and the weights and biases at the minimum of the validation error were returned. The third subset was the testing set $(\mathrm{n}=21)$, which was not used during the training and was used to evaluate performance of the different models. The Neural Network Toolbox of MATLAB 7.0.1 (MathWorks Inc., Natick, MA) was used to construct the ANN model.

\section{MLR Analysis}

The MLR model is the most commonly used technique for modeling the relationship between nutrient content and physicochemical properties in animal manure. The general form of the MLR model was

$$
\mathrm{Y}=\beta_{1} \times \mathrm{SG}+\beta_{2} \times \mathrm{EC}+\beta_{3} \times \mathrm{pH}+\beta_{4}+e,
$$

where $\mathrm{Y}=\mathrm{AN}$, TK, TN, or TP $(\mathrm{g} / \mathrm{kg}$ of fresh weight); $\beta_{\mathrm{i}}(\mathrm{i}=1,2,3,4)$ are regression parameters; $e$ is the error term; units of SG and EC are $\mathrm{g} / \mathrm{cm}^{3}$ and $\mathrm{mS} / \mathrm{cm}$, respectively.

Multiple linear regression models were developed using the Statistics Toolbox of MATLAB 7.0.1 (MathWorks Inc.). The assumptions used for MLR were that independent and dependent variables and the error term are random variables with normal distribution.

\section{PNR Analysis}

The relationship between the nutrient content and physicochemical properties was also explored by using a PNR model. The general form of the second-order PNR model was

$$
\begin{aligned}
\mathrm{Y}=\beta_{1} \times \mathrm{SG}^{2}+\beta_{2} \times \mathrm{EC}^{2}+\beta_{3} \times \mathrm{pH}^{2}+\beta_{4} \times \mathrm{SG} \times \mathrm{EC} \\
+\beta_{5} \times \mathrm{SG} \times \mathrm{pH}+\beta_{6} \times \mathrm{EC} \times \mathrm{pH}+\beta_{7} \times \mathrm{SG} \\
+\beta_{8} \times \mathrm{EC}+\beta_{9} \times \mathrm{pH}+\beta_{10}+e
\end{aligned}
$$

where $\mathrm{Y}=\mathrm{AN}, \mathrm{TK}, \mathrm{TN}$, or $\mathrm{TP}(\mathrm{g} / \mathrm{kg}$ of fresh weight $)$; $\beta_{\mathrm{i}}(\mathrm{i}=1,2, \ldots, 10)$ are regression parameters; $e$ is the error term; units of SG and EC are $\mathrm{g} / \mathrm{cm}^{3}$ and $\mathrm{mS} / \mathrm{cm}$, respectively.

Polynomial regression models were developed using the Statistics Toolbox of MATLAB 7.0.1 (MathWorks Inc.). The assumptions used for PNR were that independent and dependent variables and the error term are random variables with normal distribution.

\section{ANN Analysis}

A typical ANN consists of an input layer, a hidden layer, and an output layer. In ANN, signals are propagated from the input neurons through the hidden layer to the output neuron, and then the error is calculated and back propagated to iteratively adjust weights and biases to minimize the error in prediction; this is the most distinct character of typical back propagation algorithm (Hagan et al., 1996). In this study, 3-layer back propagation neural network models were employed. In these ANN models, the tan-sigmoid (tansig) and linear (purelin) transfer functions were used in the hidden and output layers, respectively. Using a sigmoidal-type transfer function in the hidden layer and linear transfer function in the output layer can be an advantage when it is necessary to extrapolate beyond the range of the training data (Maier and Dandy, 2000). There were 3 inputs that corresponded to the 3 physicochemical parameters of manure (SG, EC, $\mathrm{pH}$ ). Outputs were AN, TK, TN, and TP. Before the net training, all input and output values were normalized to have a zero mean and a unified standard deviation (using MATLAB's prestd function), and finally outputs were transferred back to the same units as the original outputs (using MATLAB's poststd function). After confirming the input and target of the network, network optimization was conducted. The Levenberg-Marquardt algorithm was adopted to optimize weights and biases because previous evaluations indicated that it was a suitable method for a function approximation problem where the network had less than 100 weights (Demuth and Beale, 2004). In the optimizing training process, overfitting often occurred and caused loss of generalization of the predictive model. Early stopping was a powerful and typical form using cross-validation, which was the widely used method to avoid over-fitting and improve generalization (Finnoff et al., 1993). In this study, early stopping was used in the optimizing training process.

\section{Model Evaluation}

The following parameters were calculated to evaluate model performance on the testing data set (Tedeschi, 2006): $R^{2}$ (coefficient of determination between predicted and observed values), modeling efficiency statistic (MEF), mean squared error of prediction (MSEP), mean bias, linear bias, and maximum bias (MB). The analyses of residual for mean bias and linear bias were obtained upon regression of observed values. The MB within the range of the observed values was quantified. This was done by calculating the bias at the minimum and maximum levels of the observed values. Statistical analyses were performed using the Statistics Toolbox 
of MATLAB 7.0.1 (MathWorks Inc.). Significant and highly significant differences were declared at $P<0.05$ and $P<0.01$, respectively.

\section{RESULTS AND DISCUSSION}

\section{Diversity of Collected Dairy Manures}

The statistics of the entire data set and the data set used for training and testing are given in Table 1. Specific gravity varied over a small range (1.009 to $\left.1.029 \mathrm{~g} / \mathrm{cm}^{3}\right)$ and had a mean value of $1.016 \mathrm{~g} / \mathrm{cm}^{3}$, which was similar to that reported by Piccinini and Bortone (1991). The average EC was $3.13 \mathrm{mS} / \mathrm{cm}$ with wide variation. Singh and Bicudo (2004) measured dairy manure EC of 3 counties in Kentucky and found important variation $(\mathrm{EC}=6.99,3.67$, and $7.40 \mathrm{mS} / \mathrm{cm}$ for Barren, Hart, and Monroe counties, respectively). The average $\mathrm{pH}$ was 7.31 , which was similar to that observed by Van Kessel and Reeves (2000). The average DM, AN, TK, TN, and TP concentrations were 182.30, $0.52,1.09,3.64$, and $1.09 \mathrm{~g} / \mathrm{kg}$ of fresh weight, respectively. The DM, AN, TN, and TP concentrations were comparable to the corresponding data of fresh dairy manure in previous studies (Chen et al., 2003; Chastain and Camberato, 2004). However, the TK concentration in the present study was $70 \%$ less than in other studies (Chen et al., 2003; Chastain and Camberato, 2004). Manure nutrient concentration can vary substantially and is affected by many factors such as species, age, diet of animal, and geographical region (Wilkerson et al., 1997). Scotford et al. (1998) found that TK concentration of cattle slurry varied almost 3 -fold between Germany and United Kingdom.

\section{Confirmation of ANN Model}

A previous study (Cybenko, 1989) has shown that one hidden layer neural network was enough to approximate any function, if enough hidden nodes are present. The topology of the network, along with the neuron processing function, determines the accuracy and degree of representation of the model developed to correctly represent the system behavior. Therefore, the first aim was to determine the optimal number of hidden layer nodes. There are no rigorous theoretical principles for determining it. However, there are several empirical rules (Berry and Linoff, 1997). For example, the number of neurons in the hidden layer can be confirmed by the formula: $m=\log _{2}(n)+\alpha$, where $m$ is the number of neurons in the hidden layer, $n$ is the number of input variables, and $\alpha$ is an integer between 0 and 10 (Berry and Linoff, 1997). A series of neural networks with different numbers of hidden layer nodes were trained. The number of hidden layer nodes varied from 2 to 12 . According to its generalization ability on the testing set, MSE was calculated on different numbers of the hidden layer nodes. The model that had the lowest value of MSE was chosen as the final ANN model. In the current study, the best number of hidden layer nodes was 7 for AN, 12 for TK, 9 for TN, and 8 for TP.

The training of all patterns of a training data set is called an epoch. The relationship between the training, validation, testing errors, and the epoch during the training of network is shown in Figure 1. For the ANN model of AN, training was stopped after 23 epochs because the validation error increased. For the other 3 models, the epoch number when training was stopped was 14 for TK, 14 for TN, and 16 for TP. Figure 1 indicates that the errors associated with the validation and test set were similar in characteristics. It seemed that there was no significant over-fitting during the training process.

\section{Model Comparison}

For comparison, the training and validation sets were also used to build MLR and PNR models using the

Table 1. Descriptive statistics for physicochemical parameters and nutrient content in dairy manure samples

\begin{tabular}{|c|c|c|c|c|c|c|c|c|c|}
\hline Item $^{1}$ & \multicolumn{3}{|c|}{ Training + validation data set $(\mathrm{n}=65)$} & \multicolumn{3}{|c|}{ Testing data set $(\mathrm{n}=21)$} & \multicolumn{3}{|c|}{ Entire data set $(\mathrm{n}=86)$} \\
\hline $\mathrm{SG}\left(\mathrm{g} / \mathrm{cm}^{3}\right)$ & 1.009 & 1.025 & $1.016 \pm 0.0003$ & 1.012 & 1.029 & $1.017 \pm 0.0007$ & 1.009 & 1.029 & $1.016 \pm 0.0003$ \\
\hline $\mathrm{pH}$ & 5.64 & 8.33 & $7.30 \pm 0.07$ & 5.33 & 8.62 & $7.34 \pm 0.19$ & 5.33 & 8.62 & $7.31 \pm 0.07$ \\
\hline $\mathrm{DM}(\mathrm{g} / \mathrm{kg})$ & 125.77 & 241.65 & $179.13 \pm 2.63$ & 150.37 & 325.92 & $192.11 \pm 7.50$ & 125.77 & 325.92 & $182.30 \pm 2.75$ \\
\hline $\mathrm{AN}(\mathrm{g} / \mathrm{kg})$ & 0.21 & 1.22 & $0.51 \pm 0.02$ & 0.26 & 1.50 & $0.54 \pm 0.06$ & 0.21 & 1.50 & $0.52 \pm 0.02$ \\
\hline
\end{tabular}

${ }^{1} \mathrm{SG}=$ specific gravity; $\mathrm{EC}=$ electrical conductivity; $\mathrm{AN}=$ ammonium nitrogen, $\mathrm{TK}=$ total potassium; $\mathrm{TN}=$ total nitrogen; $\mathrm{TP}=$ total phosphorus. 
(a) $\mathrm{AN}$

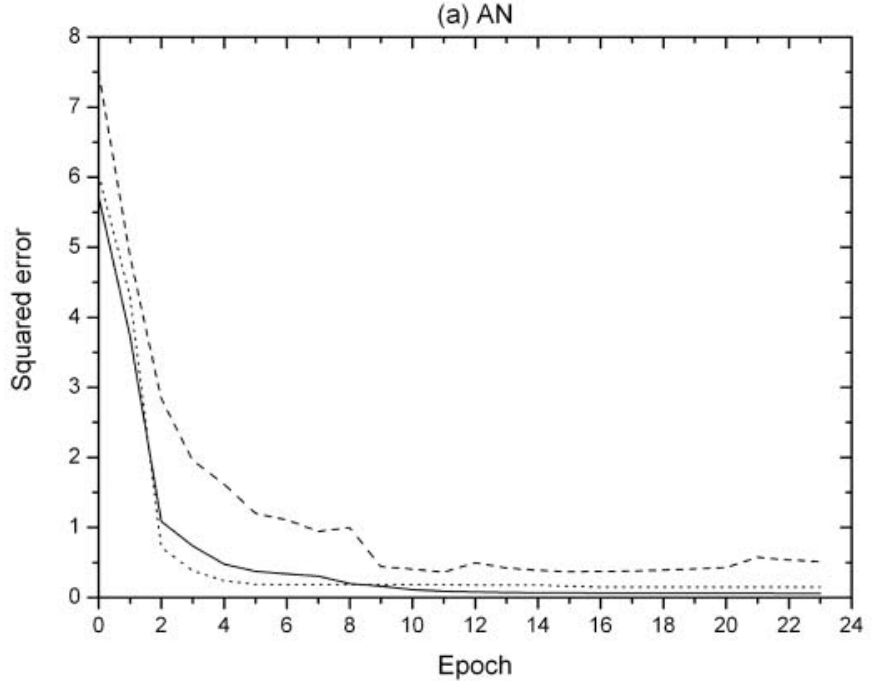

(c) $\mathrm{TN}$

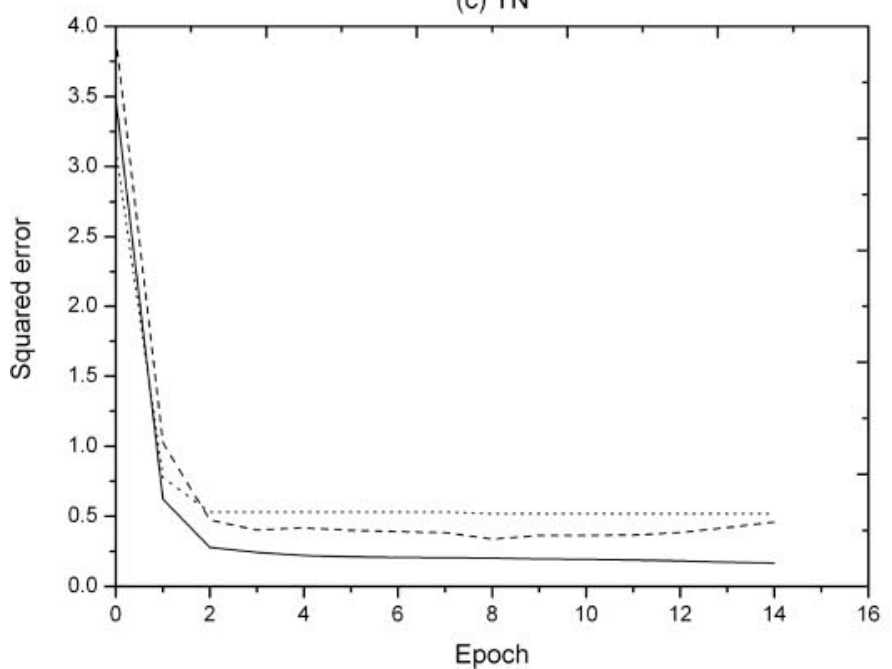

(b) TK

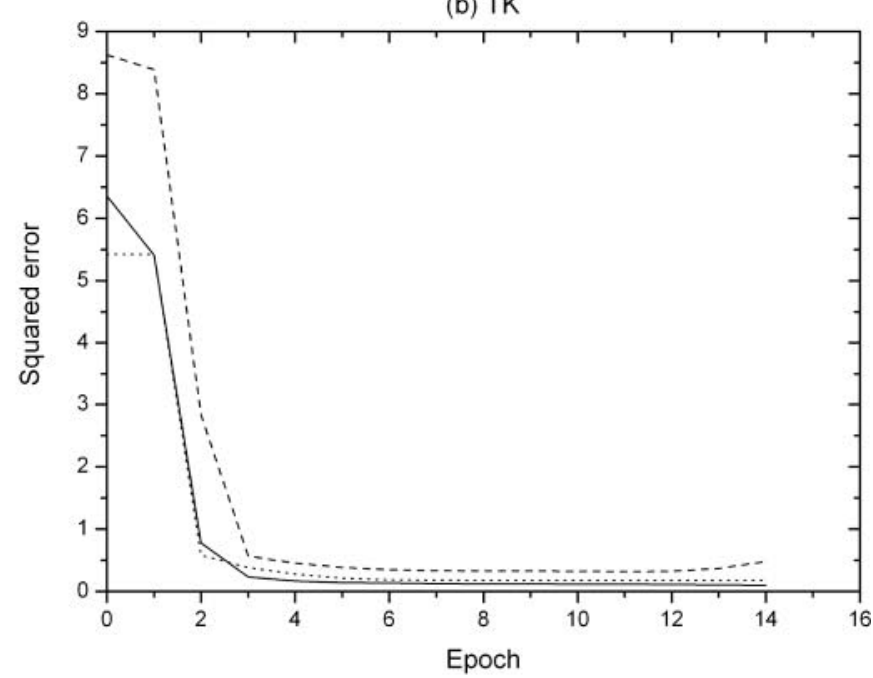

(d) TP

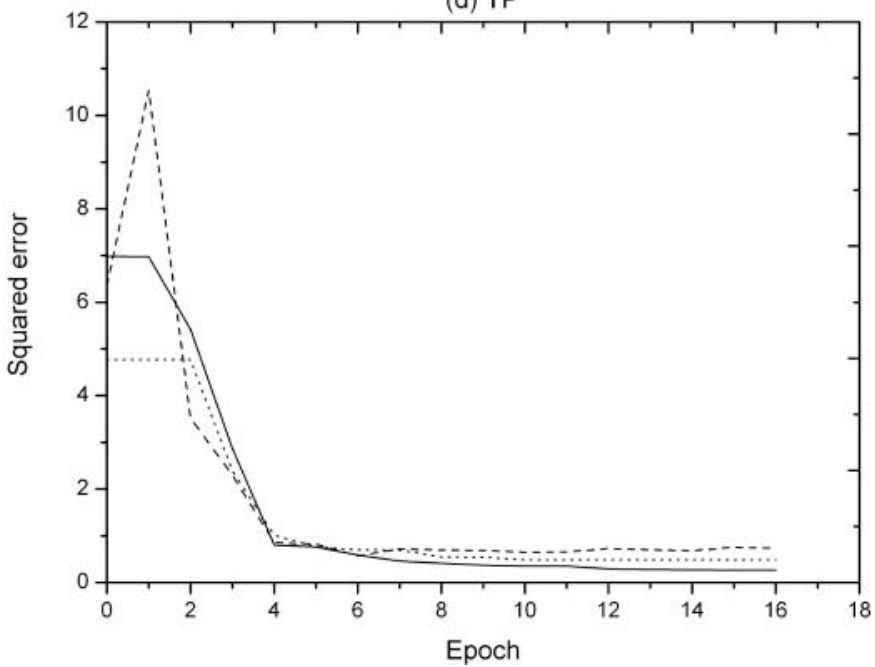

Figure 1. Plot of training (- - , validation (-----), and testing $(---)$ errors during the training process of the network constructed for the prediction of (a) ammonium N, (b) total K, (c) total N, and (d) total P.

physicochemical properties of manure. The best-fitted MLR and PNR models are listed in Tables 2 and 3. Figure 2 shows the relationship between residuals and observed manure nutrient content.

A summary of $\mathrm{R}^{2}$, MEF, MSEP, mean bias, linear bias, and MB for MLR, PNR, and ANN model predic- tions on the testing data set are listed in Table 4 . For the testing data set $(\mathrm{n}=21)$, the TK MLR model had the best prediction with $\mathrm{R}^{2}=0.83$ compared with AN, TN, and TP MLR models. The AN MLR model provided the second-best prediction with $\mathrm{R}^{2}=0.60$, as expected. The dominant cations were $\mathrm{NH}_{4}^{+}$and $\mathrm{K}^{+}$,

Table 2. Multiple linear regression equations for the nutrient content and physicochemical properties in dairy manure

\begin{tabular}{|c|c|c|c|c|c|c|c|c|c|c|c|c|}
\hline \multirow{2}{*}{$\begin{array}{l}\text { Regression } \\
\text { parameters }\end{array}$} & \multicolumn{3}{|c|}{ Ammonium N (g/kg) } & \multicolumn{3}{|c|}{ Total K (g/kg) } & \multicolumn{3}{|c|}{ Total N (g/kg) } & \multicolumn{3}{|c|}{ Total P (g/kg) } \\
\hline & Value & $\mathrm{SE}$ & $P$-value & Value & $\mathrm{SE}$ & $P$-value & Value & $\mathrm{SE}$ & $P$-value & Value & $\mathrm{SE}$ & $P$-value \\
\hline$\beta_{1}$ & -6.658 & 7.683 & 0.39 & 22.408 & 20.013 & 0.267 & 68.022 & 31.655 & 0.036 & 5.346 & 19.368 & 0.784 \\
\hline$\beta_{2}$ & 0.132 & 0.021 & $<0.001$ & 0.357 & 0.056 & $<0.001$ & 0.298 & 0.088 & 0.001 & 0.083 & 0.054 & 0.127 \\
\hline$\beta_{3}$ & 0.03 & 0.028 & 0.292 & 0.094 & 0.073 & 0.203 & -0.48 & 0.116 & $<0.001$ & -0.111 & 0.071 & 0.121 \\
\hline$\beta_{4}$ & 6.647 & 7.711 & 0.392 & -23.501 & 20.087 & 0.247 & -62.903 & 31.772 & 0.052 & -3.786 & 19.439 & 0.846 \\
\hline
\end{tabular}


Table 3. Polynomial regression equations for the nutrient content and physicochemical properties in dairy manure

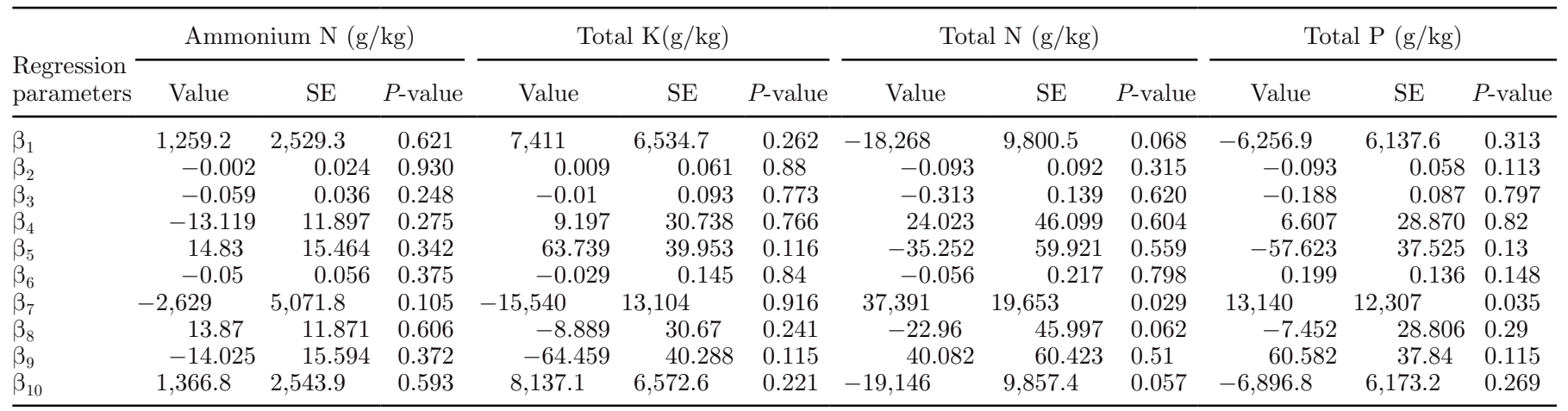

(a) AN

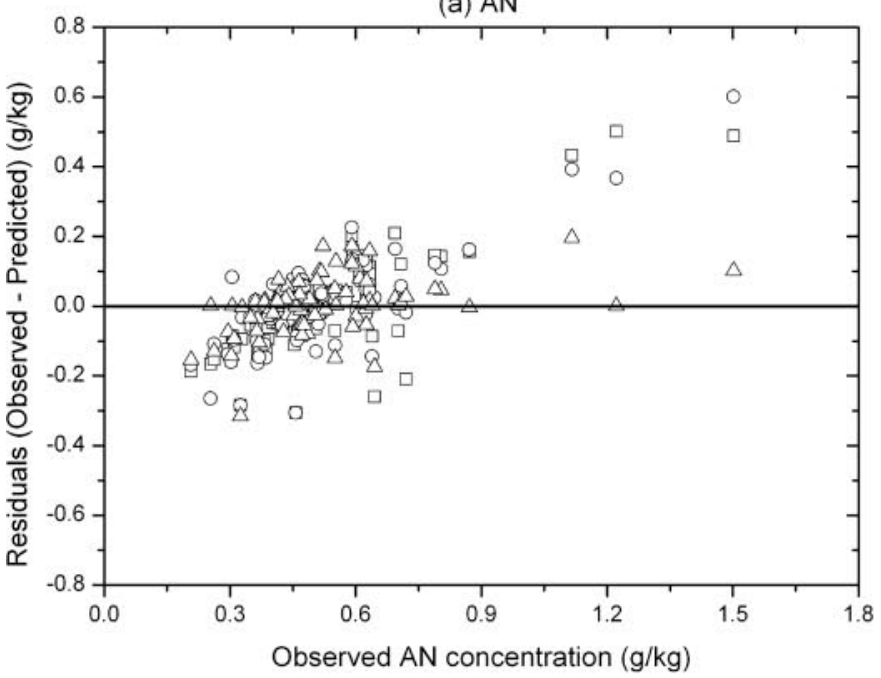

(c) $\mathrm{TN}$

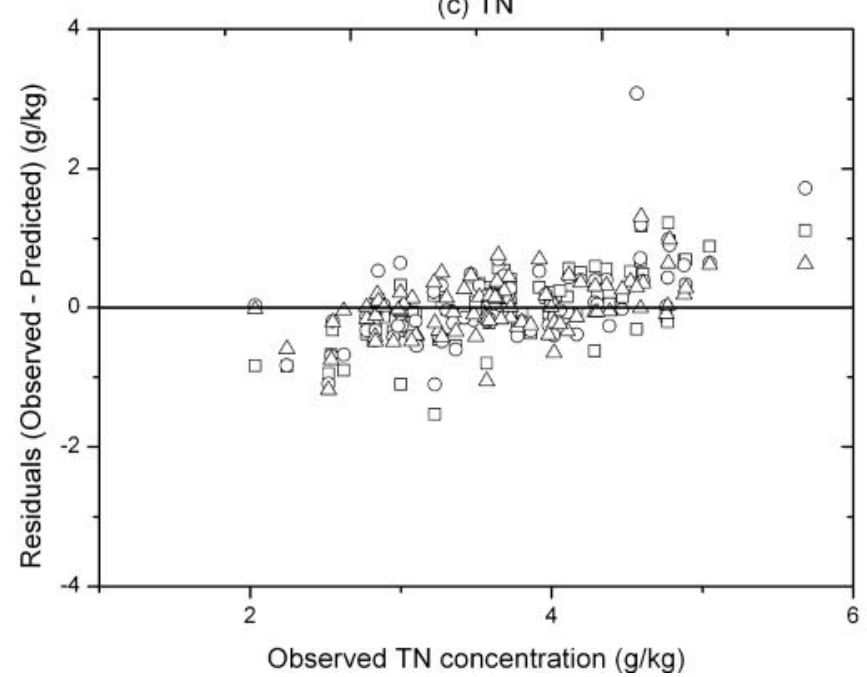

(b) TK

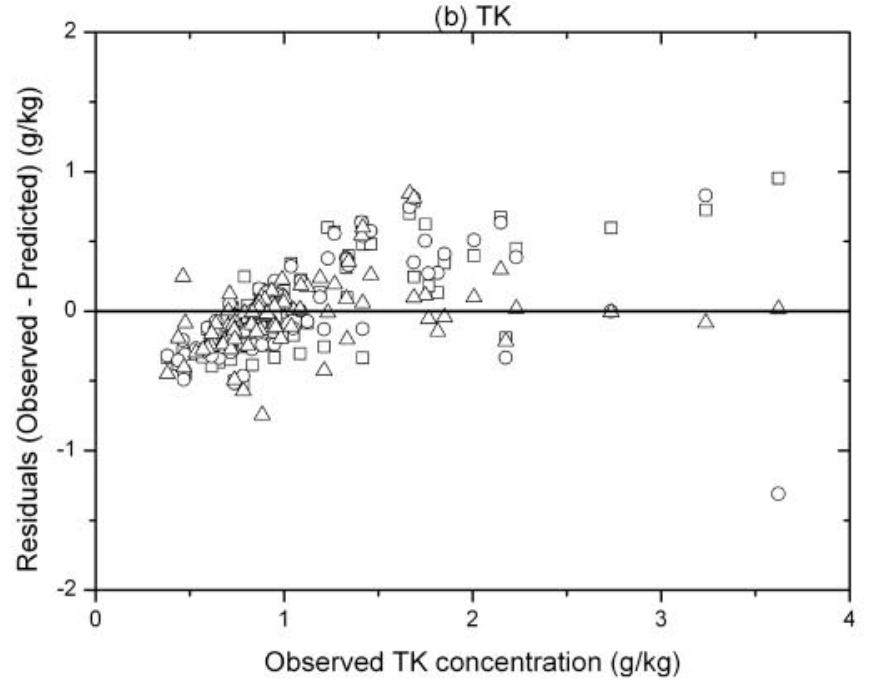

(d) TP

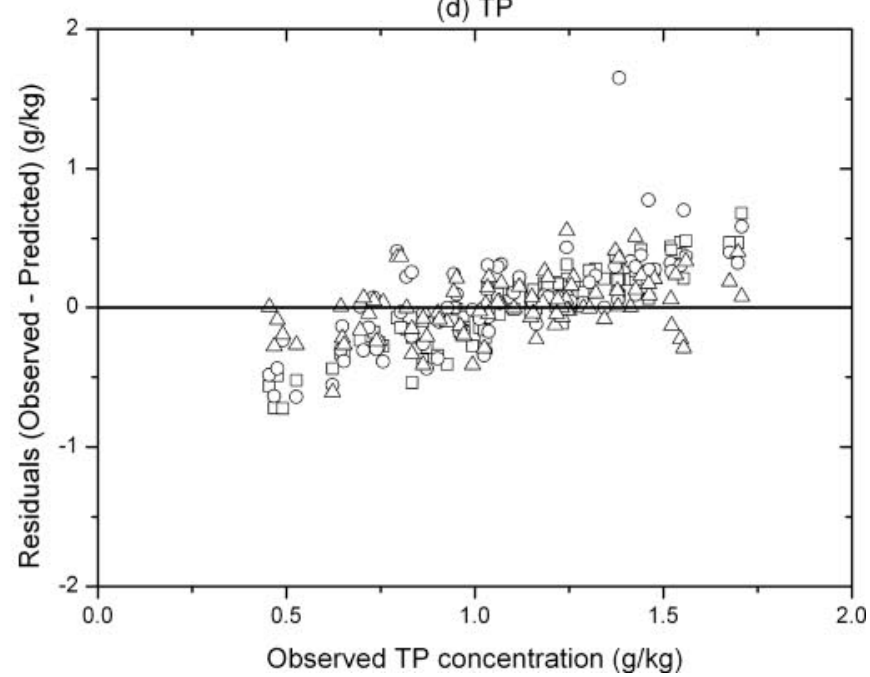

Figure 2. Residuals (observed minus predicted nutrient content) compared with the observed (a) ammonium N, (b) total K, (c) total N, and (d) total P concentrations for entire data set $(\mathrm{n}=86) ; \square=$ multiple linear regression residuals; $\mathrm{O}=$ polynomial regression residuals; $\Delta=$ artificial neural network residuals. 
Table 4. Comparison of performance of multiple linear regression (MLR), polynomial regression (PNR), and artificial neural network (ANN) models on the testing data $\operatorname{set}^{1}(n=21)$

\begin{tabular}{|c|c|c|c|c|c|c|c|c|c|}
\hline $\begin{array}{l}\text { Nutrient } \\
\text { content }(\mathrm{g} / \mathrm{kg})\end{array}$ & Model & $\mathrm{R}^{2}$ & $\mathrm{MEF}$ & MSEP & \multicolumn{2}{|c|}{ Mean bias } & \multicolumn{2}{|c|}{ Linear bias } & MB \\
\hline \multirow{2}{*}{ Ammonium N } & PNR & 0.69 & 0.56 & 0.035 & -0.30 & $<0.001$ & 0.60 & $<0.001$ & 0.60 \\
\hline & ANN & 0.83 & 0.81 & 0.015 & -0.16 & 0.007 & 0.23 & 0.011 & 0.19 \\
\hline \multirow[t]{2}{*}{ Total K } & MLR & 0.83 & 0.74 & 0.182 & -0.46 & $<0.001$ & 0.43 & $<0.001$ & 1.11 \\
\hline & PNR & 0.71 & 0.65 & 0.241 & -0.06 & NS & 0.07 & NS & 0.20 \\
\hline \multirow{2}{*}{ Total N } & PNR & 0.20 & -0.12 & 0.811 & -1.90 & 0.021 & 0.58 & 0.008 & 1.40 \\
\hline & ANN & 0.77 & 0.76 & 0.174 & -0.98 & 0.013 & 0.28 & 0.006 & 0.41 \\
\hline \multirow[t]{3}{*}{ Total P } & MLR & 0.19 & 0.19 & 0.079 & -0.86 & $<0.001$ & 0.78 & $<0.001$ & 0.46 \\
\hline & PNR & 0.003 & -1.62 & 0.256 & -0.82 & 0.018 & 0.93 & $<0.003$ & 0.76 \\
\hline & ANN & 0.49 & 0.35 & 0.063 & -0.26 & NS & 0.27 & NS & 0.20 \\
\hline
\end{tabular}

${ }^{1} \mathrm{MEF}=$ modeling efficiency statistic; MSEP = mean square error of prediction; $\mathrm{MB}=$ maximum bias.

and the concentration of each of these cations was significantly correlated with EC (Stevens et al., 1995). A similar relationship was found in previous studies (Scotford et al., 1998; Moral et al., 2005). Moral et al. (2005) observed that $\mathrm{AN}$ and $\mathrm{TK}$ in pig manure were linearly related to $\mathrm{EC}\left(\mathrm{R}^{2}=0.84\right.$ and 0.82 , respectively). The TN MLR model had a moderate prediction accuracy $\left(\mathrm{R}^{2}=0.54\right)$ for the testing set. However, the regression parameters of EC and SG were highly significant $(P$ $<0.01)$ in the TN MLR model. The result was consistent with a previous study (Moral et al., 2005) in that $\mathrm{TN}$ was linearly related to EC and $\mathrm{SG}\left(\mathrm{R}^{2}=0.83\right)$. In contrast, the TP MLR model had the worst prediction accuracy $\left(\mathrm{R}^{2}=0.19\right)$ for the testing set. Some previous studies indicated that TP can be accurately predicted by these physicochemical parameters. Scotford et al. (1998) observed that TP was closely related to SG and pH for cattle and pig manure. Van Kessel et al. (1999) found that SG can be used to predict manure TP. However, the present result was consistent with the LugoOspina et al. (2005) study in that they demonstrated a poor linear relationship between TP and SG in dairy manure. Compared with some previous MLR studies (Piccinini and Bortone, 1991; Stevens et al., 1995; Moral et al., 2005), current MLR models had limited prediction capability with low $\mathrm{R}^{2}$ value. The reasons leading to the lower $\mathrm{R}^{2}$ value is not clear because the complex nature of animal manure usually induces a very heterogeneous nutrient concentration, with a high space and time variability (Moral et al., 2005). The inconsistent prediction capability was also observed by Scotford et al. (1998). In the United Kingdom, Ireland, and Germany, the best regressions for AN were with $\mathrm{EC}\left(\mathrm{R}^{2}=0.84,0.81\right.$, and 0.92 , respectively). However, the regressions of AN with EC resulted in an $R^{2}$ value of less than 0.50 in Italy. In Ireland and Germany, the best regressions for TK were with $\mathrm{EC}\left(\mathrm{R}^{2}=0.19\right.$ and 0.80, respectively; Scotford et al., 1998).

The evaluation of the 3 models (MLR, PNR, and ANN) was carried out on the testing data set. For AN, the ANN model performed better in terms of $\mathrm{R}^{2}$, MEF, MSEP, and MB $(0.83,0.81,0.015$, and 0.19 , respectively) compared with the MLR $(0.60,0.56,0.035$, and 0.54 , respectively) and PNR (0.69, 0.56, 0.035, and 0.60 , respectively) models. The residual analysis indicated that the MLR and PNR models had significant mean bias and linear bias. However, the ANN model had lower mean bias and linear bias compared with the MLR and PNR models. Regarding TK prediction, the ANN model performed better in terms of $\mathrm{R}^{2}, \mathrm{MEF}$, and MSEP $(0.84,0.84$, and 0.112 , respectively) compared with the MLR $(0.83,0.74$, and 0.182 , respectively) and PNR (0.71, 0.65, and 0.241, respectively) models. The residual analysis revealed that the MLR model had significant mean and linear bias. The positive linear bias indicated an overprediction at a greater TK. In contrast, the PNR and ANN models had no significant mean and linear bias, and had low $\mathrm{MB}(\mathrm{MB}=0.20$ and 0.27 for the PNR and ANN models, respectively). Regarding TN, the ANN model had the best prediction, with $\mathrm{R}^{2}=0.77, \mathrm{MEF}=0.76, \mathrm{MSEP}=0.174$, and $\mathrm{MB}$ $=0.41$. The MLR model had the second-best prediction, with $\mathrm{R}^{2}=0.54, \mathrm{MEF}=0.53, \mathrm{MSEP}=0.341$, and $\mathrm{MB}=0.84$. The PNR model failed to provide a reliable prediction, with the lowest $\mathrm{R}^{2}(0.20)$ and $\operatorname{MEF}(-0.12)$, and the greatest MSEP (0.811) and MB (1.40). Figure 2 and Table 4 indicate that the TP ANN model improved results compared with the MLR and PNR models. For the testing data, the ANN model had no significant mean and linear bias, and had low $\mathrm{MB}(\mathrm{MB}=0.46$, 0.76 , and 0.20 for the MLR, PNR, and ANN models, respectively). 


\section{CONCLUSIONS}

The ANN model has the potential to predict manure nutrient concentrations more accurately than MLR and PNR models. Therefore, ANN models may be a more appropriate tool when emphasis is put on the prediction itself and not on the underlying relations between independent and dependent variables.

\section{ACKNOWLEDGMENTS}

The authors acknowledge Zengling Yang (College of Engineering, China Agricultural University, China) for her invaluable suggestions.

\section{REFERENCES}

APHA. 1998. Standard Methods for the Examination of Water and Wastewater. 20th ed. American Public Health Association, Washington, DC.

Berg, E. P., B. A. Engel, and J. C. Forrest. 1998. Pork carcass composition derived from a neural network model of electromagnetic scans. J. Anim. Sci. 76:18-22.

Berry, M. J. A., and G. Linoff. 1997. Data mining techniques for marketing, sales and customer support. John Wiley \& Sons, New York, NY.

Chastain, J. P., and J. J. Camberato. 2004. Dairy manure production and nutrient content. Pages 3a1-3a16 in Confined animal manure managers' certification program manual: Dairy version. Clemson University Extension, Clemson, SC.

Chen, S., W. Liao, C. Liu, Z. Wen, R. L. Kincaid, J. H. Harrison, D. C. Elliott, M. D. Brown, A. E. Solana, and D. J. Stevens. 2003. Value-added chemicals from animal manure. Final technical report; Contract DE-AC06-76RL01830. US Department of Energy, Washington, DC.

Chescheir, G. M., P. W. Westerman, and L. M. J. Safley. 1985. Rapid methods for determining nutrients in livestock manure. Trans. ASAE 28:1817-1824.

Cooperband, L. R., and L. W. Good. 2002. Biogenic phosphate minerals in manure: Implications for phosphorus loss to surface waters. Environ. Sci. Technol. 36:5075-5082.

Cybenko, G. C. 1989. Approximations by superpositions of a sigmoidal function. Math. Control Signal. 2:303-314.

Demuth, H. B., and M. H. Beale. 2004. Neural Network Toolbox User's Guide. The MathWorks Inc., Natick, MA.

Fernández, C., E. Soria, J. D. Martín, and A. J. Serrano. 2006. Neural networks for animal science applications: Two case studies. Expert Syst. Appl. 31:444-450.

Finnoff, W., F. Hergert, and H. G. Zimmermann. 1993. Improving model selection by nonconvergent methods. Neural Netw. 6:771783.

Fulhage, C. D. 1990. Land Application Considerations for Animal Manure. University of Missouri, Columbia.

Hagan, M. T., H. B. Demuth, and M. H. Beale. 1996. Neural Network Design. PWS Publishing Company, Boston, MA.
Lugo-Ospina, A., T. H. Dao, J. A. Van Kessel, and J. B. Reeves. 2005. Evaluation of quick test for phosphorus determination in dairy manure. Environ. Pollut. 135:155-162.

Maier, H. R., and G. C. Dandy. 2000. Neural networks for the prediction and forecasting of water resources variables: A review of modelling issues and applications. Environ. Sci. Technol. 15:101-124.

Moral, R., M. D. Perez-Murcia, A. Perez-Espinosa, J. Moreno-Caselles, and C. Paredes. 2005. Estimation of nutrient values of pig slurries in southeast Spain using easily determined properties. Waste Manag. 25:719-725.

Piccinini, S., and G. Bortone. 1991. The fertilizer value of agricultural manure: Simple rapid methods of assessment. J. Agric. Eng. Res. 49:197-208.

Scotford, I. M., T. R. Cumby, R. P. White, O. T. Carton, F. Lorenz, U. Hatterman, and G. Provolo. 1998. Estimation of the nutrient value of agricultural slurries by measurement of physical and chemical properties. J. Agric. Eng. Res. 71:291-305.

Singh, A., and J. R. Bicudo. 2004. Development of calibration curves for quick tests used in estimating nutrients from dairy wastes in Kentucky. ASAE Paper No. 044172. ASAE, St. Joseph, MI.

Stevens, R. J., C. J. O'Bric, and O. T. Carton. 1995. Estimating nutrient content of animal slurries using electrical conductivity. J. Agric. Sci. (Camb.) 125:233-238.

US Environmental Protection Agency. 1995. SW-846-EPA-3051: Microwave-assisted acid digestion of sediments, sludges, soils and oils. Test Methods for Evaluating Solid Waste. 3rd update ed. US Environmental Protection Agency, Washington, DC.

Tedeschi, L. O. 2006. Assessment of the adequacy of mathematical models. Agric. Syst. 89:225-247.

Van Kessel, J. S., and J. B. Reeves. 2000. On-farm quick tests for estimating nitrogen in dairy manure. J. Dairy Sci. 83:18371844.

Van Kessel, J. S., R. B. Thompson, and J. B. Reeves. 1999. Rapid on-farm analysis of manure nutrients using quick tests. J. Prod. Agric. 12:215-224.

Vervoort, R. W., D. E. Radcliffe, M. L. Cabrera, and M. Latimore. 1998. Nutrient losses in surface and subsurface flow from pasture applied poultry litter and composted poultry litter. Nutr. Cycl. Agroecosyst. 50:287-290.

White, H. 1990. Connectionist nonparametric regression: Multilayer feedforward networks can learn arbitrary mappings. Neural Netw. 3:535-549.

Wilkerson, V. A., D. R. Mertens, and D. P. Casper. 1997. Prediction of excretion of manure and nitrogen by Holstein dairy cattle. J. Dairy Sci. 80:3193-3204.

Xing, L., and L. J. Han. 2007. Evaluation of specific gravity and electrical conductivity for determining nutrient concentrations in suspensions of poultry manure. Pol. J. Environ. Stud. 16:919 925 .

Yang, Z. L., L. J. Han, Q. Li, and X. Piao. 2006. Estimating nutrient contents of pig slurries rapidly by measurement of physical and chemical properties. J. Agric. Sci. (Camb.) 144:261-267.

Zhang, H., T. H. Dao, N. T. Basta, E. A. Dayton, and T. C. Daniel. 2002. Remediation techniques for manure loaded soils. Pages 44 45 in National Center for Manure and Animal Waste Management. Vol. 13. F. Humenik and M. Rice, ed. MidWest Plan Service, Raleigh, NC. 